\title{
Components of the insulin resistance syndrome in seven-year-old children: relations with birth weight and the polyunsaturated fatty acid content of umbilical cord plasma phospholipids
}

\author{
P. Rump ${ }^{2}$, C.Popp-Snijders ${ }^{3}$, R. J.Heine ${ }^{3}$, G.Hornstra ${ }^{1}$ \\ ${ }^{1}$ Nutrition and Toxicology Research Institute Maastricht (NUTRIM), Maastricht University, Maastricht, The Netherlands \\ ${ }^{2}$ Department of Human Biology, Maastricht University, Maastricht, The Netherlands \\ ${ }^{3}$ Research Institute for Endocrinology, Reproduction and Metabolism, Vrije Universiteit, Amsterdam, The Netherlands
}

\begin{abstract}
Aims/hypothesis. According to the foetal origins hypothesis, there is a relation between foetal nutrition and adult glucose intolerance. In adults, insulin resistance has been associated with dietary polyunsaturated fatty acids. We examined whether the availability of polyunsaturated fatty acids during foetal life, as indicated by the fatty acid composition of cord blood samples, relates to childhood body composition and glycaemic control.

Methods. Fatty acid concentrations in umbilical cord blood were determined by gas-liquid chromatography in a birth-cohort of infants. When the children were seven years old, fasting glucose, insulin, proinsulin, and leptin levels were measured in 259 of these children, and relations with cord plasma fatty acid concentrations were studied.

Results. Cord plasma phospholipid $\gamma$-linolenic acid and dihomo- $\gamma$-linolenic acid concentrations were negatively related to insulin concentrations and calculated insulin resistance (homeostasis model assess-
\end{abstract}

ment) at seven years of age. The $\gamma$-linolenic acid concentrations were also negatively related to body fatness and proinsulin and leptin concentrations at seven years of age. No association was found for other polyunsaturated fatty acid concentrations at birth. Adjusted for age, sex, current weight, and gestational age, a lower birth weight related to higher values of insulin resistance variables. The highest insulin concentrations were found in children with a low birth weight and a low $\gamma$-linolenic acid concentration at birth. The relations between $\gamma$-linolenic acid concentration at birth and fasting insulin and calculated insulin resistance remained statistically significant when adjusted for birth weight.

Conclusion/interpretation. These findings indicate that foetal availability or metabolism of $\gamma$-linolenic acid could be involved in the early origins of insulin resistance. [Diabetologia (2002) 45: 349-355]

Keywords Polyunsaturated fatty acids, cord blood, birth weight, insulin resistance, child, foetal origins hypothesis, gamma-linolenic acid.
Insulin resistance is an important component of the metabolic syndrome that encompasses a cluster of risk factors for cardiovascular diseases including

Received: 8 August 2001 and in revised form: 1 November 2001

Corresponding author: G. Hornstra, Nutrition and Toxicology Research Institute Maastricht (NUTRIM), Maastricht University, P.O. Box 616, 6200 MD Maastricht, The Netherlands, e-mail: g.hornstra@nutrim.unimaas.nl

Abbreviations: PUFA, Polyunsaturated fatty acid; HOMA, homeostasis model assessment
Type II (non-insulin-dependent) diabetes mellitus, dyslipedaemia, obesity, and hypertension [1,2]. A small size at birth has been associated with an increased risk for the development of insulin resistance and Type II diabetes mellitus later in life [3-8]. According to the foetal origins hypothesis, which was based on these epidemiological findings, the propensity to develop insulin resistance might be a consequence of structural and functional adaptations to a limited availability of nutrients during foetal life [9]. Birth weight is, however, only a crude indicator of foetal nutrition and other environmental or genetic factors could explain the associations between size at 
birth and adult Type II diabetes mellitus. Still, there is some evidence that foetal nutrition could indeed be involved [10], like the epidemiological findings of the Dutch Hunger Winter study [11] and results from experiments in pregnant animals [12-14]. The availability or balance of particular nutrients rather than the availability of macronutrients could be important [10]. Thus far, only a limited number of human studies have been conducted on the nutritional factors that could play a role. One such group of nutrients which could be important in the foetal origins of adult diseases are essential fatty acids and their polyunsaturated derivatives $[15,16]$. The importance of the fatty acid composition of our diet for the development of insulin resistance has been recognized for some years now [17-19]. Several studies have shown that the fatty acid composition of serum lipid fractions and muscle membrane phospholipids - which at least partly reflect dietary fat quality - are closely related to insulin action [20-23]. For instance, the development of Type II diabetes has been related to lower concentrations of linoleic acid (18:2n-6) and higher concentrations of palmitoleic acid (16:1n-7), $\gamma$-linolenic acid (18:3n-6) and dihomo- $\gamma$-linolenic acid (20:3n-6) in serum cholesterol esters of 50-yearold men [24]. Previous comparisons between breastfed and bottle-fed subjects seem to indicate that nutritional factors early in life, like the availability of polyunsaturated fatty acids (PUFAs), could indeed play a role in the development of adult Type II diabetes mellitus [25,26]. Whether the foetal availability of PUFAs relates to the development of insulin resistance later in life is not known. The primary objective of our study was therefore to explore whether the availability of PUFAs in utero relates to fasting glucose, insulin, proinsulin and leptin concentrations later in life. For this purpose we conducted a follow-up study on a cohort of children in whom umbilical cord plasma phospholipid PUFA concentrations had been determined at birth. We used these umbilical cord plasma phospholipid PUFA concentrations as biomarkers of intrauterine PUFA availability.

\section{Subjects and methods}

Study cohort. Subjects were recruited from a Dutch birth-cohort of children. As infants, these children and their mothers participated in a previous study of essential fatty acids during pregnancy and pregnancy outcome. No interventions were provided. To explore the potential long-term effects of foetal essential fatty acid availability, a follow-up study was carried out between 1997 and 2000. All singleton babies born alive before 1994, and for whom an umbilical cord blood sample was available for the determination of the essential fatty acid status at birth, were included. In total, 750 children were eligible for follow-up (for more details on this cohort see ref. [27]). With the aid of the Dutch population registry, $97 \%$ of the eligible population could be traced. Three children had died and 34 lived abroad. The parents of the remaining 691 children receiv- ed a written invitation for the follow-up evaluation. We were able to contact the parents of 558 children. Of these, 297 participated, 231 refused, and 30 retracted their initial consent. Birth characteristics (ie. birth weight, crown-heel length, occipital-frontal circumference, ponderal index, gestational age, birth order) of the children who participated did not differ from the children who did not attend our clinic. Approval for this study was obtained from the Ethics Committee of the University Hospital Maastricht and the parents of all participating children gave their written informed consent.

Data collection at follow-up. All children were investigated before puberty, at about seven years of age (range: 6.7-8.1 years). The same physician (PR) examined all children and did all venipunctures. A questionnaire and a structured interview with one or both parents were used to collect additional information. Included were information on maternal smoking during pregnancy, infant nutrition, parental education, and family history of Type II diabetes. A family history of Type II diabetes was considered when a parent or grandparent of the child had Type II diabetes. Anthropometric measurements were done by one observer (PR) as previously described [28]. The percentage of body fat, fat mass, and fat-free mass were estimated from skinfold measurements using equations appropriate for children [29]. The use of other equations did not influence the main findings of this study [30].

Blood sampling and laboratory analyses. Not all parents and children agreed to a venipuncture, and no more than two puncture attempts were made. As a consequence, blood samples were obtained in 264 of the 297 children. The blood samples were collected in EDTA-treated evacuated tubes after an overnight fast. Plasma was separated from blood cells by centrifugation and stored in small portions at $-80^{\circ} \mathrm{C}$ until analysis. The fatty acid composition of plasma phospholipids was determined by capillary gas-liquid chromatography, as described before [31]. Glucose was determined enzymatically (Glucose HK-method, Hoffmann-La Roche, Basel, Switzerland) and specific insulin and total proinsulin were measured as described by Ruige et al. [32]. Plasma leptin concentration was measured using a human leptin radioimmunoassay (Linco Research, St. Charles, Miss., USA). Estimates of pancreatic beta-cell function and relative insulin resistance were calculated from the fasting insulin and glucose concentrations using the homeostasis model assessment (HOMA) equations [33].

Statistical analysis. All analyses were restricted to those children for whom a blood sample was obtained at follow-up. Five cases were excluded for missing values, leaving 259 children for analysis. Data are presented as means \pm SD, unless specified otherwise. Differences between groups were evaluated by unpaired two-tailed Student's $t$ tests or $\chi^{2}$ (chi square) tests. Linear regression models were used to explore relations between plasma phospholipid fatty acid concentrations, birth weight and the outcome variables. During these analysis continuous variables were used instead of categories. Because of a skewed distribution of some variables, log-transformed data were used when appropriate. Multiple regression models were applied to control for potential confounding factors. A two-tailed $p$ value of less than 0.05 was considered to be statistically significant. All statistical analyses were done using STATVIEW (version 4.5, Abacus Concepts Inc., Berkeley, Calif., USA). 
Table 1. Characteristics of the study population by sex

\begin{tabular}{lcc}
\hline & Boys $(n=142)$ & Girls $(n=117)$ \\
\hline Length of gestation (weeks) & $39.8(39.1 ; 41.0)$ & $39.9(39.1 ; 41.0)$ \\
Birth weight $(\mathrm{g})$ & $3377(504)$ & $3203(499)^{\mathrm{b}}$ \\
Age $(\mathrm{y})$ & $7.3(0.3)$ & $7.3(0.3)$ \\
Weight $(\mathrm{kg})$ & $25.5(4.4)$ & $24.8(4.0)$ \\
Height $(\mathrm{cm})$ & $127.8(5.0)$ & $126.1(5.9)^{\mathrm{a}}$ \\
BMI $\left(\mathrm{kg} / \mathrm{m}^{2}\right)$ & $15.4(14.3 ; 16.4)$ & $15.4(14.3 ; 16.5)$ \\
Sum four skinfolds $(\mathrm{mm})$ & $24.1(19.9 ; 26.4)$ & $28.4(23.4 ; 33.0)^{\mathrm{c}}$ \\
Body fat $(\%)$ & $16.2(13.8 ; 18.0)$ & $20.9(18.3 ; 23.7)^{\mathrm{c}}$ \\
Fat mass $(\mathrm{kg})$ & $4.1(3.2 ; 4.8)$ & $5.1(4.0 ; 6.4)^{\mathrm{c}}$ \\
Fat-free mass $(\mathrm{kg})$ & $21.1(2.7)$ & $19.4(2.3)^{\mathrm{c}}$ \\
Leptin $(\mu \mathrm{g} / \mathrm{l})$ & $2.7(1.9 ; 3.6)$ & $3.8(2.6 ; 4.9)^{\mathrm{c}}$ \\
Glucose $(\mathrm{mmol} / \mathrm{l})$ & $4.7(0.4)$ & $4.6(0.3)^{\mathrm{a}}$ \\
Insulin $(\mathrm{pmol} / \mathrm{l})$ & $32.9(25.0 ; 44.0)$ & $36.2(27.8 ; 48.0)$ \\
Proinsulin $(\mathrm{pmol} / \mathrm{l})$ & $6.4(5.4 ; 7.5)$ & $6.9(5.6 ; 8.5)^{\mathrm{a}}$ \\
Proinsulin/insulin ratio & $0.20(0.14 ; 0.25)$ & $0.19(0.15 ; 0.25)$ \\
Insulin resistance (HOMA) & $1.0(0.7 ; 1.3)$ & $1.0(0.8 ; 1.4)$ \\
beta-cell function (HOMA) & $78.1(60.6 ; 99.6)$ & $90.9(71.2 ; 123.9)^{\mathrm{b}}$ \\
\hline
\end{tabular}

BMI, body mass index, HOMA, homeostasis model assessment. Values are mean SD except for gestational age, BMI, sum four skinfolds, percent body fat, fat mass, leptin, insulin, proinsulin, and the HOMA indexes for insulin resistance and beta-cell function, where values are geometric mean (interquartile range)

${ }^{\mathrm{a}} p<0.05$

${ }^{\mathrm{b}} p<0.01$

${ }^{\mathrm{c}} p<0.001$ for differences between sexes

\section{Results}

Sex, current weight and body composition. None of the children were diabetic (fasting glucose levels $<7.0 \mathrm{mmol} / \mathrm{l}$ ). The characteristics of the participating boys and girls are reported in Table 1 . Most of the outcome variables were higher in children with a higher current weight, length, fat mass, or fatfree mass (not shown).
Relations with plasma phospholipid fatty acid composition. The most consistent relations were found between the outcome variables and the $\gamma$-linolenic acid (18:3n-6; a derivative of the essential fatty acid linoleic acid) content of the umbilical cord plasma phospholipid fraction. A higher concentration of $\gamma$-linolenic acid was associated with lower fasting insulin, proinsulin, HOMA insulin resistance, and HOMA beta-cell function (Table 2). In addition, indices of body fatness (fasting leptin, sum four skinfolds, percentage body fat, and fat mass) were also negatively related to the $\gamma$-linolenic acid levels at birth, whereas, weight, height, BMI, and fat-free mass did not relate to umbilical cord plasma $\gamma$-linolenic acid concentrations (Table 2).

In contrast, plasma phospholipid $\gamma$-linolenic acid concentration at seven years of age was positively related to the parameters of glycaemic control (fasting glucose, insulin, proinsulin, HOMA insulin resistance, and HOMA beta-cell function) and fasting leptin concentration $(p<0.05$ for all, unadjusted and adjusted for age, sex and current weight; data not shown). Plasma phospholipid $\gamma$-linolenic acid concentration at seven years of age did not relate to the anthropometric indices of body fatness (sum skinfolds, percentage body fat, or fat mass). The associations found between $\gamma$-linolenic acid concentration at birth and fasting insulin and leptin concentrations, and HOMA insulin resistance values remained statistically significant when adjusted for age, sex, current weight and the plasma phospholipid $\gamma$-linolenic acid content at seven years of age (Table 2). The associations found between $\gamma$-linolenic acid concentration at birth and indices of body fatness (sum four skinfolds, percentage body fat, and fat mass) were statistically significant $(p<0.05$ for all $)$ when adjusted for

Table 2. Unadjusted mean anthropometric measurements and biochemical parameters in 7-year-old children according to tertiles of $\gamma$-linolenic acid concentration in the plasma phospholipid fraction of umbilical cord blood at birth

\begin{tabular}{|c|c|c|c|c|c|}
\hline & \multicolumn{3}{|c|}{ Tertiles of $\gamma$-linolenic acid $(\% \mathrm{wt} / \mathrm{wt})$} & \multicolumn{2}{|l|}{$p$ for trend $\mathrm{a}^{\mathrm{a}}$} \\
\hline & $<0.04(n=85)$ & $0.04-0.07(n=87)$ & $\geq 0.07(n=87)$ & unadjusted & adjusted $^{\mathrm{b}}$ \\
\hline Weight (kg) & 25.6 & 24.9 & 25.1 & NS & NS \\
\hline Height (cm) & 127.4 & 126.7 & 127.0 & NS & NS \\
\hline $\operatorname{BMI}\left(\mathrm{kg} / \mathrm{m}^{2}\right)$ & 15.7 & 15.4 & 15.5 & NS & NS \\
\hline Sum four skinfolds (mm) & 28.7 & 26.7 & 26.6 & 0.009 & NS \\
\hline Body fat $(\%)$ & 19.8 & 18.0 & 18.4 & 0.003 & NS \\
\hline Fat mass $(\mathrm{kg})$ & 5.2 & 4.6 & 4.7 & 0.010 & NS \\
\hline Fat-free mass (kg) & 20.4 & 20.3 & 20.4 & NS & NS \\
\hline Leptin $(\mu \mathrm{g} / \mathrm{l})$ & 4.2 & 3.8 & 3.3 & 0.003 & 0.047 \\
\hline Glucose (mmol/l) & 4.7 & 4.7 & 4.6 & NS & NS \\
\hline Insulin $(\mathrm{pmol} / \mathrm{l})$ & 40.4 & 37.3 & 34.7 & 0.004 & 0.011 \\
\hline Proinsulin (pmol/l) & 7.2 & 6.9 & 6.6 & 0.025 & NS \\
\hline Proinsulin/insulin ratio & 0.20 & 0.21 & 0.22 & NS & NS \\
\hline Insulin resistance (HOMA) & 1.2 & 1.1 & 1.0 & 0.004 & 0.011 \\
\hline beta-cell function (HOMA) & 94.8 & 91.1 & 85.2 & 0.033 & NS \\
\hline
\end{tabular}

BMI, body mass index, HOMA, homeostasis model assessment, NS, not significant

${ }^{a} p$ values are derived from simple (unadjusted) and multiple

(adjusted) linear regression using continuous variables
${ }^{\mathrm{b}}$ Adjusted for sex, age, current weight and $\gamma$-linolenic acid concentration at follow-up 
Table 3. Fasting insulin concentration, proinsulin/insulin ratios and insulin resistance (HOMA) values in seven-year-old children according to tertiles of umbilical cord plasma phospholipid $\gamma$-linolenic acid concentration and birth weight

\begin{tabular}{|c|c|c|c|c|}
\hline \multirow[t]{2}{*}{ Tertiles of birth weight $(\mathrm{g})$} & \multicolumn{3}{|c|}{ Tertiles of $\gamma$-linolenic acid (\% wt/wt) } & \multirow[t]{2}{*}{$p$ for trend ${ }^{\mathrm{a}}$} \\
\hline & $<0.04$ & $0.04-0.07$ & $\geq 0.07$ & \\
\hline $\begin{array}{l}\text { Insulin }(\mathrm{pmol} / \mathrm{l}) \\
<3100 \\
3100-3500 \\
\geq 3500 \\
p \text { for trend }^{\mathrm{a}}\end{array}$ & $\begin{array}{c}44.4(35) \\
31.2(26) \\
34.7(24) \\
0.020\end{array}$ & $\begin{array}{l}34.3(24) \\
32.4(35) \\
37.6(28) \\
\text { NS }\end{array}$ & $\begin{array}{l}27.8(29) \\
34.7(27) \\
32.8(31) \\
\text { NS }\end{array}$ & $\begin{array}{l}0.001 \\
\mathrm{NS} \\
\mathrm{NS} \\
\ldots\end{array}$ \\
\hline $\begin{array}{l}\text { Proinsulin/insulin ratio } \\
<3100 \\
3100-3500 \\
\geq 3500 \\
p \text { for trend }^{\mathrm{a}}\end{array}$ & $\begin{array}{l}0.16 \\
0.21 \\
0.20 \\
0.025\end{array}$ & $\begin{array}{l}0.18 \\
0.20 \\
0.19 \\
\text { NS }\end{array}$ & $\begin{array}{c}0.23 \\
0.19 \\
0.19 \\
\mathrm{NS}\end{array}$ & $\begin{array}{l}0.011 \\
\text { NS } \\
\text { NS } \\
\ldots\end{array}$ \\
\hline $\begin{array}{l}\text { Insulin resistance (HOMA) } \\
<3100 \\
3100-3500 \\
\geq 3500 \\
p \text { for trend }^{\mathrm{a}}\end{array}$ & $\begin{array}{l}1.3 \\
0.9 \\
1.0 \\
0.013\end{array}$ & $\begin{array}{l}1.0 \\
0.9 \\
1.1 \\
\text { NS }\end{array}$ & $\begin{array}{l}0.8 \\
1.0 \\
0.9 \\
\text { NS }\end{array}$ & $\begin{array}{l}0.001 \\
\text { NS } \\
\text { NS } \\
\ldots\end{array}$ \\
\hline
\end{tabular}

Values are unadjusted geometric means (number of subjects).

${ }^{\mathrm{a}} p$ values are from multiple linear regression using continuous variables (adjusted for sex, age, current weight, length of gestation and $\gamma$-linolenic acid concentration at seven years of age)

sex, age and the plasma phospholipid $\gamma$-linolenic acid content at seven years of age. However, when also corrected for current weight, these relations were no longer significant (Table 2). No significant association or interaction was found between $\gamma$-linolenic acid concentrations at birth and $\gamma$-linolenic acid concentrations at seven years.

In addition to $\gamma$-linolenic acid, umbilical cord plasma phospholipid dihomo- $\gamma$-linolenic acid (20:3n-6; the elongation product of $\gamma$-linolenic acid) concentrations were also negatively related with fasting insulin concentration and HOMA insulin resistance at age seven ( $p<0.05$ for both, after adjustment for sex, age and current weight). Plasma phospholipid dihomo- $\gamma$-linolenic acid at seven years of age did not relate to the outcome variables. The concentration of linoleic acid (18:2n-6), arachidonic acid (20:4n-6), eicosapentanoic acid (20:5n-3), docosahexaenoic acid (22:6n-3), the sum of all $n-6$ fatty acids, the sum of all $n-6$ long-chain polyenes (20:3n-6, 20:4n-6, $22: 4 n-6$, and $22: 5 n-6$ ), the sum of all n-3 fatty acids, the sum of all $\mathrm{n}-3$ long-chain polyenes $(20: 4 \mathrm{n}-3$, $20: 5 n-3,22: 5 n-3$, and $22: 6 n-3)$ and the ratio of $n-3$ to $n-6$ fatty acids, in umbilical cord plasma phospholipids were not related any of the outcome variables. Adjustments for sex, age and current weight or for the fatty acid concentrations measured at seven years of age did not change these results.

Relations with birth weight. Children of lower birth weight had a lower fat-free mass but not a lower fat mass at age seven. After adjustment for sex, age, current weight, and length of gestation, birth weight was negatively related to BMI, sum four skinfolds, percentage body fat, fat mass, leptin, insulin, HOMA in- sulin resistance and HOMA beta-cell function (data not shown).

Low birth weight and low $\gamma$-linolenic acid concentration at birth. The highest fasting insulin concentration and HOMA insulin resistance values were seen in children of low birth weight who had a low $\gamma$-linolenic acid concentration at birth (Table 3 ). These children also had the lowest proinsulin to insulin ratio (Table 3). Additionally, children in the lowest tertile of birth weight and the lowest tertile of $\gamma$-linoleic acid concentration at birth had the highest mean fasting leptin concentration and percentage of body fat (not shown). We found no statistically significant association between birth weight and the $\gamma$-linolenic acid concentration in umbilical cord plasma phospholipids. The associations between $\gamma$-linolenic acid at birth and fasting insulin levels and HOMA insulin resistance at seven years of age remained statistically significant $(p<0.01$, for both) when adjusted for birth weight by multiple regression analysis. The product terms (birth weight $\times \gamma$-linolenic acid) for interaction were not statistically significant.

Family history of Type II diabetes mellitus. Because genetic factors play a role in the origins of insulin resistance and Type II diabetes, we investigated relations with a positive family history of diabetes mellitus. Eight children were born to mothers who reported diabetes or impaired glucose tolerance during pregnancy; 78 children had a parent or grandparent with Type II diabetes. As shown in Table 4, a low $\gamma$-linolenic acid concentration at birth was related to a positive family history of Type II diabetes mellitus. Of the 8 children born to mothers with diabetes or 
Table 4. Frequency of maternal diabetes mellitus or impaired glucose tolerance during pregnancy and of family history of Type II diabetes mellitus according to tertiles of umbilical cord plasma phospholipid $\gamma$-linolenic acid concentrations at birth

\begin{tabular}{lllc}
\hline Tertile of $\gamma$-Linolenic acid & $\begin{array}{l}\text { Maternal diabetes } \\
\text { or IGT during pregnancy }\end{array}$ & $\begin{array}{l}\text { Family history } \\
\text { of Type II diabetes }\end{array}$ & Combined \\
\hline$(\% \mathrm{wt} / \mathrm{wt})$ & $n(\%)$ & $n(\%)$ & $n(\%)$ \\
$<0.04(n=85)$ & $4(5)$ & $32(38)$ & $33(39)$ \\
$0.04-0.07(n=87)$ & $3(3)$ & $28(32)$ & $30(34)$ \\
$\geq 0.07(n=87)$ & $1(1)$ & $18(21)$ & $19(22)$ \\
$p\left(\chi^{2}\right.$-square test $)$ & NS & 0.04 & 0.04 \\
\hline
\end{tabular}

IGT, impaired glucose tolerance

Table 5. Multiple regression analyses of fasting insulin concentration and insulin resistance (HOMA) in 7-year-old children with sex, current weight, birth weight, family history of diabetes and plasma phospholipid $\gamma$-linolenic acid concentrations

\begin{tabular}{|c|c|c|}
\hline \multirow[b]{2}{*}{ Log insulin $(\mathrm{pmol} / \mathrm{l})$} & \multicolumn{2}{|c|}{$\begin{array}{l}\text { Coefficient }{ }^{\mathrm{a}}(95 \%-p \\
\text { CI) }\end{array}$} \\
\hline & & \\
\hline $\operatorname{Sex}(0=$ boy; $1=\operatorname{girl})$ & $3.2(-0.5 ; 5.8)$ & 0.019 \\
\hline Weight $(\mathrm{kg})$ & $1.0(0.7 ; 1.3)$ & $<0.001$ \\
\hline Birth weight $(\mathrm{kg})$ & $0.9(-2.3 ; 4.3)$ & 0.602 \\
\hline Family history of diabetes ${ }^{\mathrm{b}}$ & $30.1(13.0 ; 47.3)$ & $<0.001$ \\
\hline$\gamma$-Linolenic acid at birth (\%o wt/wt) & $-4.1(-7.8 ;-0.4)$ & 0.028 \\
\hline$\gamma$-Linolenic acid at 7 years $(\% \mathrm{wt} / \mathrm{wt})$ & $6.6(4.3 ; 8.9)$ & $<0.001$ \\
\hline Birth weight $\times$ family history & $-8.8(-13.9 ;-3.6)$ & $<0.001$ \\
\hline \multicolumn{3}{|l|}{ Log insulin resistance (HOMA) } \\
\hline $\operatorname{Sex}(0=$ boy; $1=\operatorname{girl})$ & $4.2(-0.3 ; 8.7)$ & 0.070 \\
\hline Weight $(\mathrm{kg})$ & $1.6(1.0 ; 2.1)$ & $<0.001$ \\
\hline Birth weight $(\mathrm{kg})$ & $1.7(-4.1 ; 7.5)$ & 0.566 \\
\hline Family history of diabetes ${ }^{\mathrm{b}}$ & $49.6(20.3 ; 78.9)$ & 0.001 \\
\hline$\gamma$-Linolenic acid at birth (\%o wt/wt) & $-7.1(-13.4 ;-0.8)$ & 0.028 \\
\hline$\gamma$-Linolenic acid at 7 years (\%o wt $/ \mathrm{wt}$ ) & $11.1(7.2 ; 15.1)$ & $<0.001$ \\
\hline Birth weight $\times$ family history & $-14.3(-23.0 ;-5.5)$ & 0.002 \\
\hline
\end{tabular}

HOMA, homeostasis model assessment

${ }^{a}$ Coefficients are percentage changes in the outcome variable per unit change in predictor variables (Note that one unit change in $\gamma$-linolenic acid concentration equals $0.1 \% \mathrm{wt} / \mathrm{wt}$ )

${ }^{b}$ Includes maternal diabetes or impaired glucose tolerance during pregnancy $(0=$ no, $1=$ yes $)$

impaired glucose tolerance during pregnancy, 7 had a below median $\gamma$-linolenic acid concentration at birth $\left(p=0.03, \chi^{2}\right.$ test $)$. Of the children with a positive family history for Type II diabetes, 51 (65\%) had a below median $\gamma$-linolenic acid concentration at birth $\left(p=0.005, \chi^{2}\right.$ test $)$. The $\gamma$-linolenic acid concentration at follow-up was not related to a maternal or family history of diabetes. Excluding children with a positive family history of diabetes from the analysis did not change the main findings of our study. Fasting plasma insulin, proinsulin, and leptin concentrations, HOMA insulin resistance, and percent body fat at age seven remained negatively associated with the $\gamma$ linolenic content of umbilical cord plasma $(p<0.05$ for all).

Multiple regression analysis. To determine how the different variables were related to fasting insulin con- centrations and HOMA insulin resistance, backward step-wise multiple regression analyses were performed (Table 5). Removed from both models $(p>0.1)$ were age and the product terms birth weight times $\gamma$ linolenic acid concentration at birth, birth weight times current weight, and family history of Type II diabetes mellitus times $\gamma$-linolenic acid concentration at birth. There was a significant interaction between birth weight and a family history of Type II diabetes mellitus (Table 5). A lower birth weight was associated with higher fasting insulin concentrations and HOMA insulin resistance values only in children with a positive family history for Type II diabetes mellitus $(p<0.001$ for both). In children with a negative family history for Type II diabetes mellitus, birth weight was not related to fasting insulin concentration nor to HOMA insulin resistance ( $p=0.6$ for both). Further adjustments for maternal smoking, infant feeding mode, maternal education, paternal education, or birth order had no major influence on the outcome.

\section{Discussion}

In this study, body composition and insulin resistance variables at seven years of age related to birth weight and PUFA concentrations in umbilical cord blood. This data suggests that a low intrauterine availability of $\gamma$-linolenic acid could predispose individuals to increased body fatness and insulin resistance later in life. This would be in accordance with the general concept of the foetal origin hypothesis that a limited availability of nutrients early in life could have detrimental effects for the subsequent development of insulin resistance and Type II diabetes [9].

Similar to previous studies conducted in adults and children [3-8, 34], we found that (after correction for sex, age, current weight and length of gestation) a small size at birth related to higher values of the insulin resistance variables and an increased body fatness later in life. In our cohort of seven-year-olds, a low birth weight not only related to a higher fasting insulin concentration and the HOMA index for insulin resistance, but also to higher values of HOMA beta-cell function and lower proinsulin-to-insulin ratios. These 
findings support an association between birth weight and insulin resistance, but do not indicate a relation with an impaired beta-cell function.

In this study, fasting insulin concentrations and the HOMA index for insulin resistance were highest in children who had a low birth weight in combination with a low umbilical cord plasma phospholipid $\gamma$-linolenic acid concentration. After adjustment for birth weight, cord blood $\gamma$-linolenic acid concentration remained associated with HOMA insulin resistance and fasting insulin levels. We found no significant relation between birth weight and the $\gamma$-linolenic acid content of umbilical cord plasma phospholipids. Therefore, the association between cord blood $\gamma$-linolenic acid concentrations and childhood insulin resistance does not seem to be mediated through a reduction in foetal growth. According to a previous study [11], poor nutrition during late gestation could lead to permanent changes in insulin-glucose metabolism, even when the effects on intrauterine growth are small.

It is not clear how $\gamma$-linolenic acid influences insulin metabolism. Suggested mechanisms explaining the effects of dietary fatty acids on insulin metabolism involve changes in number and affinity of insulin receptors, alterations in membrane fatty-acid composition, changes in the translocation of glucose transporters, changes in intracellular glucose storage, or alterations in the expression of lipogenic and glycolytic genes $[17,19,35]$. Such mechanisms could involve the so-called peroxisome proliferator-activated receptors (PPARs) [35]. Gamma-linolenic acid has been shown to have a relatively high affinity for $\operatorname{PPAR} \alpha$ and $\operatorname{PPAR} \delta$, these transcription factors playing central roles in glucose and lipid homeostasis [36, 37].

The observed association between a low $\gamma$-linolenic acid concentration in umbilical cord plasma phospholipids and the insulin-resistance variables at age seven could reflect a genetic predisposition rather than a limited $\gamma$-linolenic acid availability dependent on maternal dietary intake. Investigators have shown that the muscle membrane fatty acid composition of children relates to maternal indices of insulin resistance [38]. They postulate that a genetic predisposition for the incorporation, elongation and desaturation of specific fatty acids is inherited by the child and contributes to the risk for future development of insulin resistance [38]. In this study, a positive family history of diabetes was related to a lower $\gamma$-linolenic acid content of umbilical cord plasma phopholipids. However, the associations found between $\gamma$-linolenic acid concentration at birth and the insulin resistance variables at age seven were independent of family history. It thus seems that the associations found do not simply reflect a genetic predisposition.

The observed associations between $\gamma$-linolenic acid concentrations at birth and at seven years of age on one hand and the insulin resistance variables on the other hand could be an epiphenomenon. Insulin plays a crucial role in fatty acid metabolism and is known to enhance the activity of the enzyme delta6-desaturase [39]. Delta-6-desaturase stimulates the conversion of linoleic acid (18:2n-6) into $\gamma$-linolenic acid. A higher plasma concentration of insulin could thus explain a higher $\gamma$-linolenic acid content of plasma lipid fractions. Conversely, low levels of circulating insulin could relate to lower $\gamma$-linolenic acid concentrations. Findings in (Type I) (insulin-dependent) diabetes mellitus patients [40] and animal models of reduced beta-cell function [41] indicate that insulin deficiency relates to a lower delta-6-desaturase activity, which can be restored by insulin treatment. The associations found between plasma phospholipid $\gamma$-linolenic acid concentration and the insulin resistance variables could thus reflect such a 'mechanism' of reverse causality. Furthermore, less then $40 \%$ of the children participated during the follow-up study. Although the birth characteristics (including $\gamma$-linolenic concentration at birth) of the children who participated did not differ from the children who did not attend our clinic, residual bias due to selection cannot be excluded.

In conclusion, the results of the present explorative study indicate that a limited availability of $\gamma$-linolenic acid early in human life could be one of the factors involved in the foetal origins of insulin resistance.

Acknowledgements. This study was sponsored by the Dutch Organization for Scientific Research (NWO, grant number: 90462 186) and by the University Hospital of Maastricht. The fatty acid analyses were financed by Numico Research, Wageningen, The Netherlands (no conflicts of interest). We like to thank J. van den Berg for performing the fatty acid analyses.

\section{References}

1. Pyorala K (1979) Relationship of glucose tolerance and plasma insulin to the incidence of coronary heart disease: results from two population studies in Finland. Diabetes Care 2: 131-141

2. Reaven GM (1988) Banting lecture 1988. Role of insulin resistance in human disease. Diabetes 37: 1595-1607

3. Barker DJP, Hales CN, Fall CHD, Osmond C, Phillips K, Clark PMS (1993) Type II (non-insulin-dependent) diabetes mellitus, hypertension, and hyperlipidaemia (syndrome $\mathrm{X})$ : relation to reduced foetal growth. Diabetologia 36 : 62-67

4. Hales CN, Barker DJP, Clark PMS et al. (1991) Fetal and infant growth and impared glucose tolerance at age 64 . BMJ 303: 1019-1022

5. Lithell HO, McKeigue PM, Berglund L, Mohson R, Lithell UB, Leon DA (1996) Relation of size at birth to non-insulin-dependent diabetes and insulin concentrations in men aged 50-60 years. BMJ 312: 406-410

6. Curhan GC, Willett WC, Rimm EB, Spiegelman D, Ascherio AL, Stampfer MJ (1996) Birth weight and adult hyper- 
tension, diabetes mellitus, and obesity in US men. Circulation 94: 3246-3250

7. Law CM, Gordon GS, Shiell AW, Barker DJP, Hales CN (1995) Thinness at birth and glucose tolerance in sevenyear-old children. Diabet Med 12: 24-29

8. Bavdekar A, Yajnik CS, Fall CHD et al. (1999) Insulin resistance syndrome in 8-year-old Indian children. Diabetes 48: 2422-2429

9. Barker DJP (1998) Mothers, babies and health in later life. 2nd edn. Churchill Livingstone, Edinburgh

10. Harding JE (2001) The nutritional basis of the fetal origins of adult disease. Int J Epidemiol 30: 15-23

11. Ravelli ACJ, van der Meulen JH, Osmond C, Barker DJP, Bleker OP (1998) Glucose tolerance in adults after in utero exposure to the Dutch Famine. Lancet 351: 173-177

12. Dahri S, Snoeck A, Reusens-Billen B, Remacle C, Hoet JJ (1991) Islet function in offspring of mothers on low-protein diet during gestation. Diabetes 40: 115-120

13. Langley SC, Browne RF, Jackson AA (1994) Altered glucose tolerance in rats exposed to maternal low protein diets in utero. Comp Biochem Physiol Physiol 109: 223-229

14. Desai M, Crowther NJ, Ozanne SE, Lucas A, Hales CN (1995) Adult glucose and lipid metabolism may be programmed during fetal life. Biochem Soc Trans 23: 331-335

15. Olson SF (1994) Further on the association between retarded foetal growth and adult cardiovascular disease. Could low intake of marine diets be a common cause? J Clin Epidemiol 47: 565-569

16. James WPT (1997) Long-term fetal programming of body composition and longevity. Nutr Rev 55: S31-S43

17. Storlien LH, Baur LA, Kriketos AD et al. (1996) Dietary fats and insulin action. Diabetalogia 39: 621-631

18. Storlien LH, Kritekos AD, Calvert GD, Baur LA, Jenkins AB (1997) Fatty acids, triglycerides and syndromes of insulin resistance. Prostaglandins Leukot Essent Fatty Acids 57: 379-385

19. Vessby B (2000) Dietary fat and insulin action in humans. Br J Nutr 83: S91-S96

20. Salomaa V, Ahola I, Tuomilehto J et al. (1990) Fatty acid composition of serum cholesterol esters in different degrees of glucose intolerance: a population-based study. Metabolism 39: 1285-1291

21. Borkman M, Storlien LH, Pan DA, Jenkins AB, Chisholm DJ, Campbell LV (1993) The relation between insulin sensitivity and the fatty-acid composition of skeletal-muscle phospholipids. N Eng J Med 328: 238-244

22. Vessby B, Tengblad S, Lithell H (1994) Insulin sensitivity is related to the fatty acid composition of serum lipids and skeletal muscle phospholipids in 70-year-old men. Diabetologia 37: 1044-1050

23. Pan DA, Lilioja S, Milner MR et al. (1995) Skeletal muscle membrane lipid composition is related to adiposity and insulin action. J Clin Invest 96: 2802-2808

24. Vessby B, Aro A, Skarfors E, Berglund L, Salminen I, Lithell $\mathrm{H}$ (1994) The risk to develop NIDDM is related to the fatty acid composition of serum chelesterol esters. Diabetes 43: 1353-1357

25. Baur LA, O'Conner J, Pan DA, Kriketos AD, Storlien LH (1998) The fatty acid composition of skeletal muscle mem- brane phospholipid: its relation with the type of feeding and plasma glucose levels in young children. Metabolism 47: 106-112

26. Pettit DJ, Forman MR, Hanson RL, Knowler WC, Bennett PH (1997) Breast feeding and incidence of non-insulin-dependent diabetes mellitus in Pima Indians. Lancet 350: 166-168

27. Rump P, Mensink RP, Kester ADM, Hornstra G (2001) Essential fatty acid composition of plasma phospholipids and birth weight: a study in term neonates. Am J Clin Nutr 73: 797-806

28. Gerver WJM, de Bruin R (1996) Paediatric morphometrics: a reference manual. Bunge, Utrecht

29. Weststrate JA, Deurenberg P (1989) Body composition in children: proposal for a method for calculating body fat percentage from total body density or skinfold-thickness measurements. Am J Clin Nutr 50: 1104-1115

30. Slaughter MH, Lohman TG, Boileau RA et al. (1988) Skinfold equations for estimation of body fatness in children and youth. Hum Biol 60: 709-723

31. Al MD, van Houwelingen AC, Kester AD, Hasaart TH, de Jong AE, Hornstra G (1995) Maternal essential fatty acid patterns during normal pregnancy and their relationship to the neonatal essential fatty acid status. Br J Nutr 74: $55-68$

32. Ruige JB, Dekker JM, Nijpels G et al. (1999) Hyperproinsulinaemia in impaired glucose tolerance is associated with a delayed insulin response to glucose. Diabetologia 42: $177-180$

33. Matthews DR, Hosker JP, Rudenski AS, Naylor BA, Treacher DF, Turner RC (1985) Homeostasis model assessment: insulin resistance and $\beta$-cell function from fasting glucose and insulin concentrations in man. Diabetologia 28: 412-419

34. Hediger ML, Overpeck MD, Kuczmarski RJ, McGlynn A, Maurer KR, Davis WW (1998) Muscularity and fatness of infants and young children born small-for-gestational-age. Pediatrics 102: E60

35. Clarke SD, Jump DB (1996) Polyunsaturated fatty acid regulation of hepatic gene transcription. Lipids 31: S7-S11

36. Xu HE, Lambert MH, Montana VG et al. (1999) Molecular recognition of fatty acids by peroxisome proliferator-activated receptors. Mol Cell 3: 397-403

37. Gervois P, Torra IP, Fruchart JC, Steals B (2000) Regulation of lipid and lipoprotein metabolism by PPAR activators. Clin Chem Lab Med 38: 3-11

38. Baur LA, O'Connor J, Pan DA, Storlien LH (1999) Relationships between maternal risk of insulin resistance and the child's muscle membrane fatty acid composition. Diabetes 48: 112-116

39. Brenner RR (1981) Nutritional and hormonal factors influencing desaturation of essential fatty acids. Prog Lipid Res 20: $41-47$

40. Horrobin DF (1993) Fatty acid metabolism in health and disease: the role of delta-6-desaturase. Am J Clin Nutr 57: 732S-737S

41. Mohan IK, Das UN (2000) Prevention of chemically induced diabetes mellitus in experimental animals by polyunsaturated fatty acids. Nutrition 17: 126-151 